\title{
Overexpression of orotate phosphoribosyl transferase in hormone-refractory prostate cancer
}

\author{
TOMOAKI TANAKA, HIDENORI KAWASHIMA, KENTARO MATSUMURA, \\ TOMOKO YAMASHITA-HOSONO, RIKIO YOSHIMURA, \\ KATSUYUKI KURATSUKURI, KOJI HARIMOTO and TATSUYA NAKATANI
}

Department of Urology, Osaka City University Graduate School of Medicine, Osaka, Japan

Received April 14, 2008; Accepted June 18, 2008

DOI: $10.3892 /$ or_00000186

\begin{abstract}
Orotate phosphoribosyl transferase (OPRT) is the initial enzyme of 5-fluorouracil (5-FU) activation, in which 5-FU is converted to 5-fluorouridinemonophosphate. Dihydropyrimidine dehydrogenase (DPD) is a degrading enzyme that catabolizes 5-FU. In this study, we investigated the expression of these enzymes in normal prostate gland (NP), hormone-sensitive prostate cancer (HSPC) and hormonerefractory prostate cancer (HRPC). Forty-two prostatic tissue specimens were obtained from patients who had undergone prostate needle biopsies without any treatments or with PSA failure after initial androgen deprivation. The tissue samples derived from formalin-fixed, paraffin-embedded sections were made by laser-captured microdissection and from those RNA was extracted. The levels of OPRT and DPD mRNA expression were examined by quantitative reverse transcriptase-polymerase chain reaction (RT-PCR). The level of OPRT mRNA expression in the HSPC or the HRPC specimens was significantly higher than that in the NP specimens. Immunohistochemical staining for OPRT revealed strong expression of OPRT in prostate cancer cells. There was a significant correlation between OPRT mRNA expression levels and the tumor pathological grade. Furthermore, the OPRT/DPD expression ratio, a powerful predictive factor to evaluate 5-FU sensitivity, in the HRPC group was significantly higher than that in the low grade HSPC group. Thus, 5-FU may be an effective option for some HRPC patients.
\end{abstract}

\section{Introduction}

5-Fluorouracil (5-FU) is a chemotherapeutic agent used against a variety of cancers, including prostate cancer (1-4). A previous study has demonstrated that the response rate of single agent 5-FU against hormone-refractory prostate cancer

Correspondence to: Dr Tomoaki Tanaka, Department of Urology, Osaka City University Graduate School of Medicine, 1-4-3 Asahimachi, Abeno-ku, Osaka 545-8585, Japan

E-mail: tomoaki826@msic.med.osaka-cu.ac.jp

Key words: orotate phosphoribosyl transferase, 5-fluorouracil, hormone-refractory prostate cancer
(HRPC) was $\sim 30 \%$ (2). 5-FU is converted to the active metabolic forms, fluorodeoxyuridine monophosphate (FdUMP), which exerts its anticancer effect through the inhibition of thymidylate synthase (TS), a key enzyme of DNA synthesis. Dihydropyrimidine dehydrogenase (DPD) is the first and rate-limiting enzyme of 5-FU catabolism and degradates 5-FU (5). Some studies have demonstrated that DPD expression was elevated in those cancer cells which had a low sensitivity to 5-FU $(6,7)$. In the anabolic pathway of 5-FU, orotate phosphoribosyl transferase (OPRT) is the most important enzyme for phosphorylation of 5-FU. It metabolizes 5-FU to 5-fluorouridinemonophosphate (FUMP), which predominantly inhibits RNA synthesis (1). Recent studies have suggested that the increased expression and activity of OPRT induces a high sensitivity to 5-FU in several tumor types (8-11). Although there have been some studies showing the therapeutic efficacy of 5-FU in some HRPC patients $(3,12,13)$, the sensitivity to 5-FU in individual prostate cancer patients remains difficult to predict.

The quantitative analysis of the expression of the above enzymes may contribute to the prediction of the efficacy of 5-FU administration and the overall outcome in prostate cancer patients. In the present study, we investigated the correlation between the expression of OPRT and DPD and tissue characteristics such as malignancy, pathological grade and hormone sensitivity.

\section{Materials and methods}

Patients and tissue samples. We obtained 37 specimens of prostate cancer that were collected by needle biopsy at Osaka City University Hospital. The specimens comprised hormonesensitive prostate cancer without any treatments and hormone-refractory prostate cancer with PSA failure after the initial androgen deprivation. The pathological data of those samples are listed in Table I. A total of 5 biopsy specimens with normal prostate gland were obtained from patients who had been diagnosed as having no malignancy.

Microdissection. A representative formalin-fixed, paraffinembedded tumor specimen was selected by a pathologist after examination of the hematoxylin and eosin-stained slides. Sections $(10 \mu \mathrm{m})$ were stained with neutral fast red to enable visualization of histology for laser capture micro-dissection (P.A.L.M. Microlaser Technologies AG, Munich, Germany), 
which was performed to ensure that only tumor cells were studied. Tissue collected from specimens confirmed by histopathology as having no cancer invasion was considered to be normal tissue.

RNA extraction and cDNA synthesis. RNA was isolated from formalin-fixed, paraffin-embedded (FFPE) specimens using a novel, proprietary procedure (Response Genetics, Los Angeles, CA: United States Patent Number 6,248,535). After RNA isolation, cDNA was derived from each sample according to a previously described procedure (14).

PCR quantification of $m R N A$ expression. Target cDNA sequences were amplified by quantitative PCR using a fluorescence-based real-time detection method [ABI PRISM 7900 Sequence Detection System (Taq Man); Applied Biosystems, Foster City, CA], as previously described $(15,16)$. The $25 \mu 1 \mathrm{PCR}$ reaction mixture contained $600 \mathrm{nmol} / \mathrm{l}$ of each primer (Table II), $200 \mathrm{nmol} / \mathrm{l}$ each of dATP, dCTP and dGTP, 400 umol/l dUTP, $5.5 \mathrm{mmol} / 1 \mathrm{MgCl}_{2}$ and $1 \mathrm{X}$ Taq Man buffer A containing a reference dye (all reagents were supplied by Applied Biosystems). The PCR conditions were $50^{\circ} \mathrm{C}$ for $10 \mathrm{sec}$ and $95^{\circ} \mathrm{C}$ for $10 \mathrm{~min}$, followed by 42 cycles at $95^{\circ} \mathrm{C}$ for $15 \mathrm{sec}$ and $60^{\circ} \mathrm{C}$ for $1 \mathrm{~min}$. OPRT and DPD mRNA levels were quantified as ratios between two measurements (target gene/ß-actin).

Immunohistochemistry. A Vectastain ABC kit (Vector Laboratories, Burlingame, CA, USA) was used for immunohistochemical staining according to the manufacturer's instructions. After deparaffinization and rehydration, sections were incubated with $0.03 \%$ hydrogen peroxide in methanol for $30 \mathrm{~min}$ and treated sequentially with normal goat serum, polyclonal rabbit antibody against human OPRT (1:1500 dilution, Taiho Pharmaceutical, Saitama, Japan) overnight at $4^{\circ} \mathrm{C}$. The secondary antibody with the avidin-biotin-peroxidase complex was visualized using diaminobenzidine. The sections were counterstained lightly with hematoxylin for microscopic examination. Control immunohistochemical staining was performed using no primary antibody and preabsorption of the primary antibody with antigen prior to incubation.

Statistical analysis. Data analysis was performed using a Student's t-test. $\mathrm{P}<0.05$ was considered to denote statistical significance.

\section{Results}

OPRT MRNA expression in normal prostate gland (NP), hormone-sensitive prostate cancer (HSPC) and hormonerefractory prostate cancer (HRPC) specimens. OPRT mRNA expression levels in hormone-sensitive prostate cancer (HSPC) tissues or hormone-refractory prostate cancer (HRPC) tissues were significantly higher than those in normal prostate gland (NP) tissues respectively ( $\mathrm{p}=0.046,0.007$ ), as shown in Fig. 1.

OPRT mRNA expression in relation to the pathological grade. OPRT expression levels in HRPC were significantly higher than those in hormone-sensitive low grade tumors (well and moderately differentiated adenocarcinomas) ( $\mathrm{p}=0.035$; Fig. $2 \mathrm{~A}$ ).
Table I. Characteristics of 37 prostate cancer specimens.

\begin{tabular}{|c|c|c|}
\hline Number & Tumor grade & Gleason score \\
\hline 1 & Well & 6 \\
\hline 2 & Well & 6 \\
\hline 3 & Well & 6 \\
\hline 4 & Well & 7 \\
\hline 5 & Well & 6 \\
\hline 6 & Well & 6 \\
\hline 7 & Well & 6 \\
\hline 8 & Well & 6 \\
\hline 9 & Well & 6 \\
\hline 10 & Mod & 6 \\
\hline 11 & Mod & 6 \\
\hline 12 & Mod & 8 \\
\hline 13 & Mod & 8 \\
\hline 14 & Mod & 8 \\
\hline 15 & Mod & 9 \\
\hline 16 & Mod & 7 \\
\hline 17 & Mod & 7 \\
\hline 18 & Mod & 7 \\
\hline 19 & Mod & 7 \\
\hline 20 & Mod & 7 \\
\hline 21 & Poor & 8 \\
\hline 22 & Poor & 8 \\
\hline 23 & Poor & 10 \\
\hline 24 & Poor & 10 \\
\hline 25 & Poor & 10 \\
\hline 26 & Poor & 10 \\
\hline 27 & Poor & 10 \\
\hline 28 & Poor & 10 \\
\hline 29 & Poor & 9 \\
\hline 30 & Poor & 9 \\
\hline 31 & Poor & 9 \\
\hline 32 & Poor & 9 \\
\hline 33 & Poor (HRPC) & 10 \\
\hline 34 & Poor (HRPC) & 10 \\
\hline 35 & Poor (HRPC) & 10 \\
\hline 36 & Poor (HRPC) & 10 \\
\hline 37 & Poor (HRPC) & 10 \\
\hline
\end{tabular}

Well, well differentiated adenocarcinoma; mod, moderately differentiated adenocarcinoma; poor, poorly differentiated adenocarcinoma and HRPC, hormone-refractory prostate cancer.

The expression levels of OPRT in specimens with a Gleason score of $<7$ were significantly lower than those in specimens with a Gleason score of $\geq 7$ or HRPC respectively ( $\mathrm{p}=0.045$, 0.045; Fig. 2B).

$O P R T / D P D$ expression ratio in relation to the pathological grade. There was no significant difference between DPD mRNA expression and the tumor pathological grade (data not shown). It has also been shown that a high OPRT/DPD ratio correlates with a good response to 5-FU-based chemotherapy in colorectal tumors. The OPRT/DPD 
Table II. PCR primers and probes.

Primer/Probe

OPRT5-496F (25 bp)

OPRT5-586R (20 bp)

Probe OPRT5-528T (27 bp)

DPD3a-51 F (19 bp)

DPD3a-134R (20 bp)

Probe DPD3a-71 T (29 bp)

ß-actin-592F (18 bp)

B-actin-651 R (22 bp)

Probe B-actin-611 T (18 bp)
Sequence

TAGTGTTTTGGAAACTGTTGAGGTT

CTTGCCTCCCTGCTCTCTGT

6FAM-TGGCATCAGTGACCTTCAAGCCCTCCT

AGGACGCAAGGAGGGTTTG

GTCCGCCGAGTCCTTACTGA

6FAM-CAGTGCCTACAGTCTCGAGTCTGCCAGTG

TGAGCGCGGCTACAGCTT

TCCTTAATGTCACGCACGATTT

6FAM-ACCACCACGGCCGAGCGG

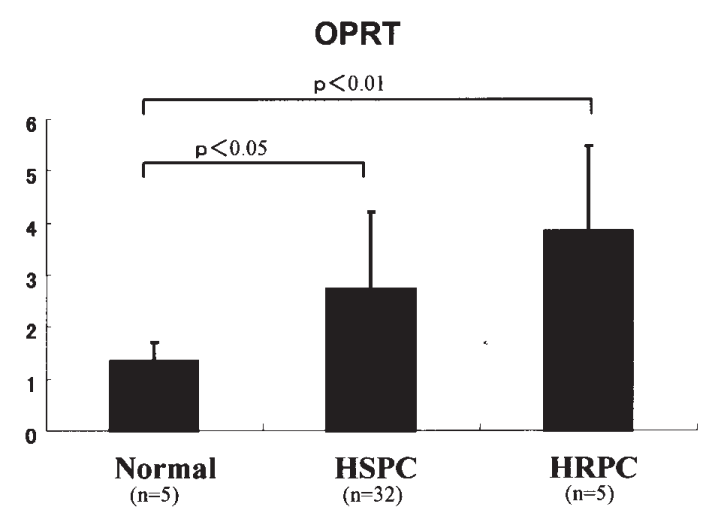

Figure 1. OPRT mRNA expression levels in normal prostate gland (NP), hormone-sensitive prostate cancer (HSPC) and hormone-refractory prostate cancer (HRPC) specimens. OPRT mRNA expression level in HSPC or HRPC was significantly higher than that in NP respectively (Student's t-test, $\mathrm{p}<0.05$ ). Values are presented as mean $\pm \mathrm{SD}$.

expression ratio in HRPC specimens was significantly higher than that in hormone-sensitive low grade tumors (well and moderately differentiated adenocarcinomas) ( $\mathrm{p}=0.021$; Fig. 3 ).

Expression of OPRT protein in relation to the pathological grade. The immunohistochemical staining for OPRT revealed the strong expression of OPRT in the specimens with both hormone-sensitive poorly differentiated adenocarcinomas and HRPC (Fig. 4). The pattern of granular staining was detected around the nucleus and in the nucleus of cancer cells as demonstrated by the immunohistochemical findings. On the contrary, the level of OPRT staining in normal prostate gland tissues was very weak. Furthermore, OPRT expression was observed in a homogeneous pattern within the cytoplasm of hormone-sensitive well and moderately differentiated adenocarcinoma cells.

\section{Discussion}

This study demonstrated that the mRNA expression levels of OPRT in prostate cancer with or without hormone sensitivity were higher than those in normal prostate gland, that the levels of OPRT expression in the specimens with HRPC were higher than those in hormone-sensitive low grade prostate cancers,
$\mathbf{A}$

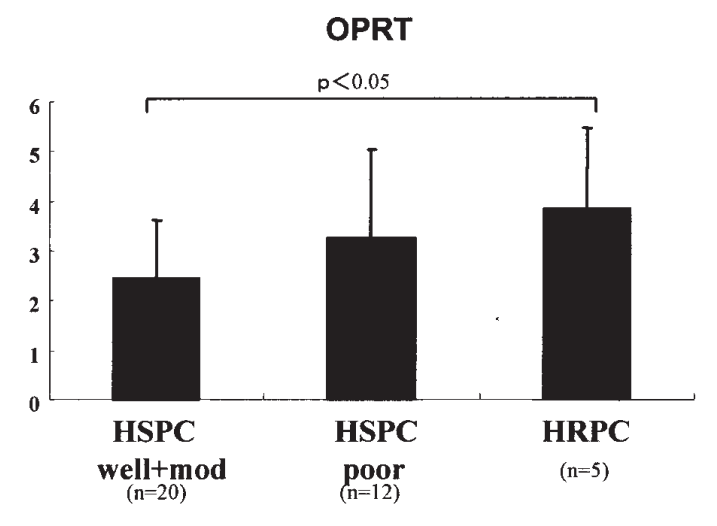

B

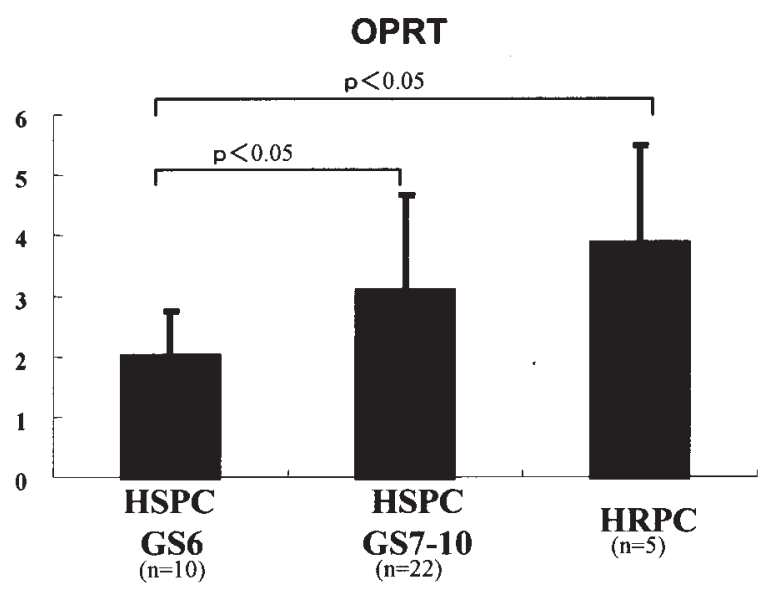

Figure 2. Relationship between OPRT mRNA expression level and pathological tumor grade. (A) OPRT mRNA expression level in HRPC specimens was significantly higher than that in low grade (well and moderately differentiated) prostate cancer tissues (Student's t-test, $\mathrm{p}<0.05$ ). (B) OPRT mRNA expression level in cases of prostate cancer with a Gleason score of $<7$ was significantly lower than that in prostate cancer with a Gleason score of $\geq 7$ or HRPC, respectively (Student's t-test, $\mathrm{p}<0.05$ ). Values are presented as mean $\pm \mathrm{SD}$.

and that the levels of OPRT expression in specimens with a Gleason score of $<7$ were lower than those in specimens with a Gleason score of $\geq 7$ or HRPC, using quantitative RT-PCR 


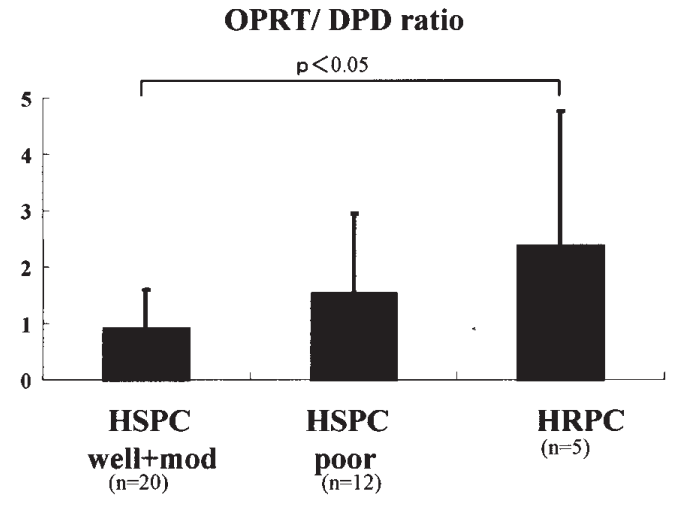

Figure 3. Relationship between OPRT/DPD expression ratio and pathological tumor grade. OPRT/DPD expression ratio in HRPC specimens was significantly higher than that in low grade (well and moderately differentiated) prostate cancer tissues. (Student's t-test, $\mathrm{p}<0.05$ ). Values are presented as mean $\pm \mathrm{SD}$.

analysis. OPRT metabolizes 5-FU into FUMP as the initial step of the 5-FU metabolic pathway. In several tumor types, a high expression of OPRT is associated with a high sensitivity to 5-FU-based chemotherapy. In urological tumors, Mizutani et al reported that a high level of OPRT expression was correlated with high grade tumors, advanced clinical stage and a high sensitivity to 5-FU in renal cell carcinoma and bladder cancer $(17,18)$. Miyoshi et al demonstrated that high OPRT expression levels were correlated with high grade tumors in hormone-sensitive prostate cancer (19).

DPD is a catabolic enzyme in the degradation of 5-FU. In some tumors, the high DPD expression is correlated with resistance to 5-FU, tumor aggressiveness and a poor prognosis
(20-22). Moreover, a higher OPRT/DPD expression ratio has been associated with a good response to 5-FU and longer survival in metastatic colorectal tumors (23). Our data revealed that the OPRT/DPD ratio in HRPC was significantly higher than that in low grade HSPC. Interestingly, the pattern of immunohistochemical staining and distribution of OPRT expression in high grade HSPC or HRPC was different from that in low grade HSPC (Fig. 4). Oeda et al demonstrated that the pattern of immunohistochemical staining and distribution of OPRT expression in gastric cancer cells were altered by tumor aggressiveness (24). To the best of our knowledge, this study is the first to exhibit the expression of OPRT and DPD in the specimens with HRPC. Theoretically, HRPC with high OPRT and low DPD expression may have potential sensitivity to 5-FU. With respect to the biological findings, the exogenous overexpression of OPRT enhances the effect of 5-FU on gastric cancer cells (25). On the contrary, downregulation of OPRT with a small interfering RNA decreases the sensitivities of some tumor cells to 5-FU (8). Further studies are necessary to elucidate the association between OPRT expression and 5-FU sensitivity in prostate cancer cells. Recently, Miyazaki et al demonstrated that some chemotherapeutic agents and cytokines influenced the expression of 5-FU metabolic enzymes and the sensitivity to 5-FU in colon cancer cells (26). Wada et al revealed that the synergistic antitumor effect of docetaxel and S-1 was induced by downregulation of the expression and activity of DPD and upregulation of those of OPRT via biochemical modulation of two drugs in gastric cancer cells (9). In the future, the regulation of OPRT and DPD by the novel biochemical modulation may contribute to the efficacy of 5-FU-based chemotherapy against HRPC.
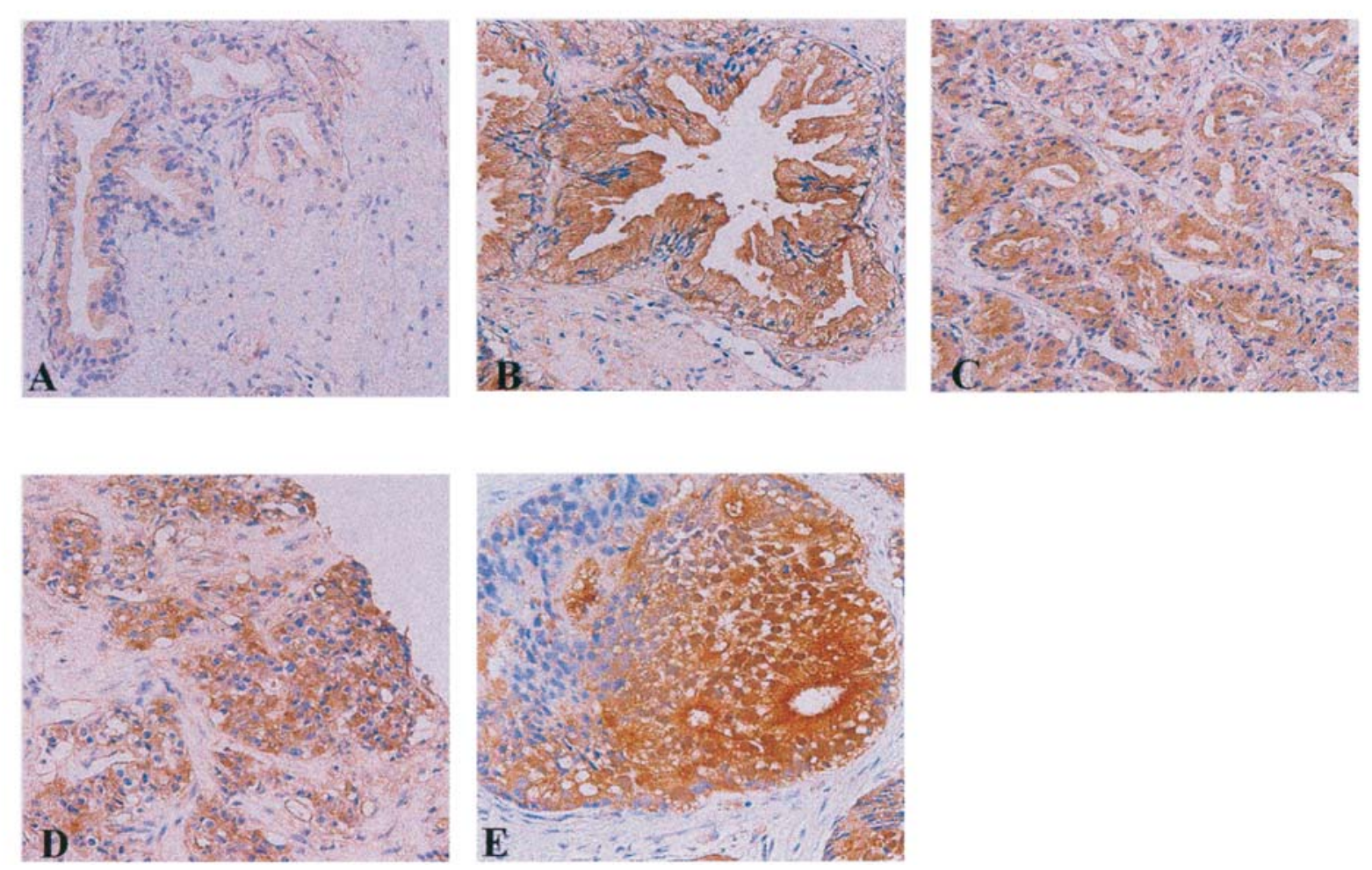

Figure 4. Expression of OPRT protein in normal prostate gland, hormone-sensitive prostate cancer and hormone-refractory prostate cancer specimens. (A) OPRT was expressed weakly in the cytoplasm of normal prostate gland cells. (B and C) OPRT showed a homogeneous distribution in the cytoplasm of hormonesensitive well and moderately differentiated adenocarcinoma cells. (D and E) A granular staining pattern of OPRT was detected in the nucleus and around the nucleus of hormone-sensitive poorly differentiated adenocarcinoma and hormone-refractory prostate cancer cells. (A-E) x400 magnification. 


\section{Acknowledgements}

We thank Taiho Pharmaceutical Co. for providing us with polyclonal rabbit antibody against human OPRT. We thank Sakae Masaki for technical assistance. This study was supported by grants from the Ministry of Education, Science, and Culture of Japan and Osaka City University Medical Research Foundation.

\section{References}

1. Longley DB, Harkin DP and Johnston PG: 5-fluorouracil: mechanisms of action and clinical strategies. Nat Rev Cancer 3: 330-338, 2003

2. Miyake H, Hara I, Yamazaki $\mathrm{H}$ and Eto $\mathrm{H}$ : Clinical outcome of oral uracil/tegafur (UFT) therapy for patients with hormone refractory prostate cancer. Oncol Rep 14: 673-676, 2005.

3. Bhandari MS, Pienta KJ, Fardig J, Olson K and Smith DC: Phase II trial of oral uracil/tegafur plus leucovorin in patients with hormone-refractory prostate carcinoma. Cancer 106: 1715-1721, 2006.

4. Hoshi S, Ohyama C, Hagisawa S, Ono K, Satoh M, Saito S, Fukuzaki A and Arai Y: Complete regression of bone metastases on super bone scan, by low-dose cisplatin, UFT, diethylstilbestrol diphosphate, and dexamethasone in a patient with hormonerefractory prostate cancer. Int J Clin Oncol 8: 118-120, 2003.

5. Kubota T: 5-fluorouracil and dihydropyrimidine dehydrogenase. Int J Clin Oncol 8: 127-131, 2003.

6. Isshi K, Sakuyama T, Gen T, Nakamura Y, Kuroda T, Katuyama T and Maekawa Y: Predicting 5-FU sensitivity using human colorectal cancer specimens: comparison of tumor dihydropyrimidine dehydrogenase and orotate phosphoribosyl transferase activities with in vitro chemosensitivity to 5-FU. Int J Clin Oncol 7: 335-342, 2002.

7. Oguri T, Achiwa H, Bessho Y, Muramatsu H, Maeda H, Niimi T, Sato $\mathrm{S}$ and Ueda R: The role of thymidylate synthase and dihydropyrimidine dehydrogenase in resistance to 5-fluorouracil in human lung cancer cells. Lung Cancer 49: 345-351, 2005.

8. Sakamoto E, Nagase H, Kobunai T, Oie S, Oka T, Fukushima M and Oka T: Orotate phosphoribosyltransferase expression level in tumors is a potential determinant of the efficacy of 5fluorouracil. Biochem Biophys Res Commun 363: 216-222, 2007.

9. Wada Y, Yoshida K, Suzuki T, Mizuiri H, Konishi K, Ukon K, Tanabe K, Sakata Y and Fukushima M: Synergistic effects of docetaxel and $\mathrm{S}-1$ by modulating the expression of metabolic enzymes of 5-fluorouracil in human gastric cancer cell lines. Int J Cancer 119: 783-791, 2006.

10. Fujii R, Seshimo A and Kameoka S: Relationships between the expression of thymidylate synthase, dihydropyrimidine dehydrogenase, and orotate phosphoribosyltransferase and cell proliferative activity and 5-fluorouracil sensitivity in colorectal carcinoma. Int J Clin Oncol 8: 72-78, 2003.

11. Katsumata K, Tomioka H, Sumi T, Yamashita S, Takagi M, Kato F, Nakamura R, Koyanagi Y, Aoki T and Kato K: Correlation between clinicopathologic factors and kinetics of metabolic enzymes for 5-fluorouracil given to patients with colon carcinoma by two different dosage regimens. Cancer Chemother Pharmacol 51: 155-160, 2003.

12. Birtle AJ, Newby JC and Harland SJ: Epirubicin carboplatin and 5-fluorouracil (ECarboF) chemotherapy in metastatic hormone refractory prostate cancer. Br J Cancer 91: 1472-1476, 2004.
13. Droz JP, Muracciole X, Mottet N, Ould Kaci M, Vannetzel JM, Albin N, Culine S, Rodier JM, Misset JL, Mackenzie S, Cvitkovic E and Benoit G: Phase II study of oxaliplatin versus oxaliplatin combined with infusional 5-fluorouracil in hormone refractory metastatic prostate cancer patients. Ann Oncol 14: 1291-1298, 2003.

14. Lord RV, Salonga D, Danenberg KD, Peters JH, DeMeester TR, Park JM, Johansson J, Skinner KA, Chandrasoma P, DeMeester SR, Bremner CG, Tsai PI and Danenberg PV: Telomerase reverse transcriptase expression is increased early in the Barrett's metaplasia, dysplasia, adenocarcinoma sequence. J Gastrointest Surg 4: 135-142, 2000.

15. Heid CA, Stevens J, Livak KJ and Williams PM: Real time quantitative PCR. Genome Res 6: 986-994, 1996.

16. Gibson UE, Heid CA and Williams PM: A novel method for real time quantitative RT-PCR. Genome Res 6: 995-1001, 1996

17. Mizutani Y, Wada H, Yoshida O, Fukushima M, Nakanishi H and Miki T: Significance of orotate phosphoribosyltransferase activity in renal cell carcinoma. J Urol 171(2 Pt 1): 605-610, 2004.

18. Mizutani Y, Wada H, Fukushima M, Yoshida O, Nakanishi H, Li YN and Miki T: Prognostic significance of orotate phosphoribosyltransferase activity in bladder carcinoma. Cancer 100: 723-731, 2004

19. Miyoshi Y, Uemura H, Ishiguro H, Kitamura H, Nomura N, Danenberg PV and Kubota Y: Expression of thymidylate synthase, dihydropyrimidine dehydrogenase, thymidine phosphorylase, and orotate phosphoribosyl transferase in prostate cancer. Prostate Cancer Prostatic Dis 8: 260-265, 2005.

20. Yoshinare K, Kubota T, Watanabe M, Wada N, Nishibori H, Hasegawa H, Kitajima M, Takechi T and Fukushima M: Gene expression in colorectal cancer and in vitro chemosensitivity to 5-fluorouracil: a study of 88 surgical specimens. Cancer Sci 94 : 633-638, 2003.

21. Tokunaga Y, Nakagami M, Tokuka A and Ohsumi K: Prognostic effects of dihydropyrimidine dehydrogenase in advanced colorectal cancer after surgery: immunohistochemistry using a new monoclonal antibody. Anticancer Res 23: 1763-1768, 2003.

22. Horiguchi J, Takei H, Koibuchi Y, Iijima K, Ninomiya J, Uchida K, Ochiai R, Yoshida M, Yokoe T, Iino Y and Morishita Y: Prognostic significance of dihydropyrimidine dehydrogenase expression in breast cancer. Br J Cancer 86: 222-225, 2002

23. Ichikawa W, Uetake H, Shirota Y, Yamada H, Takahashi T, Nihei Z, Sugihara K, Sasaki Y and Hirayama R: Both gene expression for orotate phosphoribosyltransferase and its ratio to dihydropyrimidine dehydrogenase influence outcome following fluoropyrimidine-based chemotherapy for metastatic colorectal cancer. Br J Cancer 89: 1486-1492, 2003.

24. Oeda M, Yoshida K, Sanada Y, Wada Y, Suzuki T, Mizuiri H, Konishi K, Shigematsu H, Tanabe K and Fukushima M: The expression profiles of orotate phosphoribosyltransferase and dihydropyrimidine dehydrogenase in gastric cancer and their clinical significance. Oncol Rep 16: 1165-1172, 2006.

25. Taomoto J, Yoshida K, Wada Y, Tanabe K, Konishi K, Tahara H and Fukushima M: Overexpression of the orotate phosphoribosyltransferase gene enhances the effect of 5-fluorouracil on gastric cancer cell lines. Oncology 70: 458-464, 2006.

26. Miyazaki K, Shibahara T, Sato D, Uchida K, Suzuki H, Matsui H, Yanaka A, Nakahara A and Matsuzaki Y: Influence of chemotherapeutic agents and cytokines on the expression of 5 -fluorouracil-associated enzymes in human colon cancer cell lines. J Gastroenterol 41: 140-150, 2006. 